Vol 11, Issue 9, 2018

\title{
IDENTIFICATION OF BIOACTIVE COMPOUNDS IN CYMODOCEA SERRULATA-A SEAGRASS BY GAS CHROMATOGRAPHY-MASS SPECTROSCOPY
}

\author{
PUSHPABHARATHI N, JAYALAKSHMI M, AMUDHA P, VANITHA V* \\ Department of Biochemistry, Vels Institute of Science Technology and Advance Science, Pallavaram, Chennai - 600 039 , Tamil Nadu, India. \\ Email: vanitha.sls@velsuniv.ac.in \\ Received: 17 April 2018, Revised and Accepted: 29 May 2018
}

\begin{abstract}
Objective: The objective of this study was to identify the lead phytocompounds present in the ethanol extract of the seagrass Cymodocea serrulata by gas chromatography-mass spectrometry (GCMS).
\end{abstract}

Methods: $1 \mathrm{~kg}$ of $C$. serrulata whole seagrass powder was subjected to extraction on polarity basis using five solvent such as hexane, chloroform, ethyl acetate, ethanol, and water. Since ethanol extract showed a maximum antioxidant property, its phytochemicals were investigated using GCMS technique. The phytocompounds identified through GC were interpreted with mass spectra national institute standard and technology library.

Result: The GCMS analysis of ethanol extract of $C$. serrulata identified peaks of six different compounds they are hexahydrofarnesyl acetone (7.70\%), hexadecanoic acid, methyl ester (4.11\%), tetradecanoic acid (62.89\%), pentadecanoic acid(62.89\%), cholesta4, 6dien3ol (5.88\%), and stigmasterol $(19.42 \%)$

Conclusion: The GCMS study of $C$. serrulata ethanol extract unveils the presence of bioactive compounds that have a pharmacological and nutraceutical values.

Keywords: Gas chromatography-mass spectrometry, Cymodocea serrulata, Seagrass, Palmitic acid, Phytocompounds.

(C) 2018 The Authors. Published by Innovare Academic Sciences Pvt Ltd. This is an open access article under the CC BY license (http://creativecommons. org/licenses/by/4. 0/) DOI: http://dx.doi.org/10.22159/ajpcr.2018.v11i9.26744

\section{INTRODUCTION}

Our ancestor lived a life with a quote "food as a medicine." In midgeneration, people forgot about traditional foods, especially herbs come to know about various new diseases that are epidemic to humankind. In past decades, attention was turned toward the ethnobotanical use of our traditional herbs; it is mainly because of an outbreak of multiple resistance of pathogen against antibiotics. To search a novel and potent therapeutic agent, it is directed to look into the marine source, which yet has to be explored. Recently, there are many biologically active compounds such as fucoidans, phlorotannins, pigments, and phycocolloids were discovered from marine sources [1]. When we look into marine habitats, marine angiosperms are unique, they occupy the bottom line of food chain serve as main nutrients for the ocean higher organisms. Seagrass is marine angiosperm that grows and completes their lifecycle submerged under the ocean. Their structural organization and phytochemical composition are in such a way to adapt and protect themselves from salinity, wave strength, microorganism, epiphytes, and predation [2]. In folk medicine, Cymodocea serrulata, a seagrass commonly known as karumbu passi has been used as a food and also as a medicine by coastal region people and by fishermen while traveling in the sea [3]. It is used as a tranquilizer for babies as soothing helps during pregnancy and against cough and malaria. C. serrulata is seen abundant in South Indian coastal region. Although there is a report on the antibacterial, antioxidant, and anti-inflammatory property of $C$. serrulata, there are no evident details on phytocompounds present in it [4]. In the present study, the ethanol extract of $C$. serrulata was subjected to GC and mass spectroscopy analysis to elucidate the phytocompounds present behind their bioactivity.

\section{METHODS}

\section{Collection of seagrass}

The fresh seagrass C. serrulata was collected from Thirupalaikudi, Ramanathapuram district, coastal region during June by skilled divers.
It has been identified and authenticated by Dr. N.kaliaperumal, Former Principal Scientist, CMFRI (ICAR, Govt. of India). The collected seagrass was washed thoroughly and shade dried. Then, the dried $C$. serrulata was powdered and preserved in an airtight container.

\section{Extraction}

$150 \mathrm{~g}$ of dried seagrass powder was soaked in 1:2 ratio in each solvent for 3 days successively in increasing polarity order through hexane, chloroform, ethyl acetate, ethanol, and aqueous at room temperature. The extracts were collected and filtered through Whatman filter paper and shade dried. As per the previous study, ethanol extract of C. serrulata shows an efficient antioxidant activity; thus, the ethanol extract of $C$. serrulata was subjected to gas chromatography-mass spectrometry (GCMS) analysis.

\section{GCMS}

The phytocompounds present in ethanol extract of $C$. serrulata was identified using GC SHIMADZU QP2010 equipment. In this instrument, gas chromatogram was integrated with a mass spectrometer in such a way that the mass analyzer and detector were directly connected to the capillary column (RXI-17sil MS $30 \mathrm{~m} \times 0.25 \mathrm{~mm} \times 0.25 \mu$ ). While detection, electron ionization energy of $70 \mathrm{eV}$ was utilized and helium gas of $99.999 \%$ pure was used as a carrier gas at a constant flow rate of $1.5 \mathrm{ml} / \mathrm{min}$. The sample was injected at $2 \mu \mathrm{l}$ injection volume, the injector temperature and ion source temperature was set at $200^{\circ} \mathrm{C}$. At $70 \mathrm{eV}$, mass spectra were carried out with a scan interval of $0.5 \mathrm{~s}$ at a $40-1000 \mathrm{~m} / \mathrm{z}$ scan range. The total GC running time was $35 \mathrm{~min}$. By comparing the average peak area to the total area, the relative percentage amount of each component was calculated. GCMS solution version 2.6 software was used for detection.

\section{Identification of compound}

The phytocompounds were identified by comparing the spectrum of know component to the spectrum of the unknown component. 
The software used will identify the compound by using similarity search, similarity search with index, and index search methods. The interpretation of mass spectrum was done with libraries such as the National Institute Standard and Technique, which has more than 62,000 patterns, Wiley, drug library, FFNSC library (flavor and fragrance). The name, molecular weight, molecular formula, and structure of the compound were determined.

\section{RESULT}

The GCMS analysis of ethanol extract of the seagrass $C$. serrulata identified about nine bioactive components. Fig. 1 represents the chromatogram of different phytocompounds present in the ethanol extract of $C$. serrulata. Their principles of retention time, molecular weight, molecular formula, and peak area are given in Table 1.

The bioactive components identified are hexahydrofarnesyl acetone, hexadecanoic acid methyl ester, n-hexadecanoic acid, tetradecanoic acid, pentadecanoic acid, cholesta4,6dien3ol, and stigmasterol. At single retention time 18.86, there are three major components palmitic acid, myristic acid, and pentadecanoic acid were identified. They have the highest peak value of $62.89 \%$. The derivative of stigmasterol, stigmasta5, and 22-dien3ol acetate was identified at the high peak level of $19.42 \%$. Palmitic acid esters were identified to be at $14.11 \%$. The two components hexahydrofarnesyl acetone and 2undecanone 6,10dimethyl were identified to be at the peak value of $7.70 \%$. The other two components are stigmasterol, and Cholesta-4,6-dien 3ol were at $5.88 \%$. The structure of these compounds identified through GCMS is given in Table 2 .

\section{DISCUSSION}

The GCMS analysis of ethanol extract of C. serrulata reveals the presence of phytocompounds that are biologically active. According to the chromatogram obtained by GCMS ethanol extract of $C$. serrulata consists of palmitic acid, myristic acid, and pentadecanoic acid as a major component. They may be produced by the plant defense itself from stress as secondary metabolites. These phytoprotectants proved to possess pharmacological activity acts in similar away as synthetic drugs [12]. The palmitic acid reported possessing anticancer activity, antimicrobial, and nematicide activity. The palmitic acid increases the number of probiotic bacteria in the gut; thus, they involved in the development of intestine [13]. It is required in the biosynthesis of lung lecithin, which is related to fetal maturation as well as it has been reported that presence of palmitic acid in the Nigerian meal can partly be related to the low incidence of respiratory disease [14]. Palmitic acid reported inhibiting human hepatoma cell growth in a dosedependent and time-dependent manner. Thus, they possess anticancer activity [15].

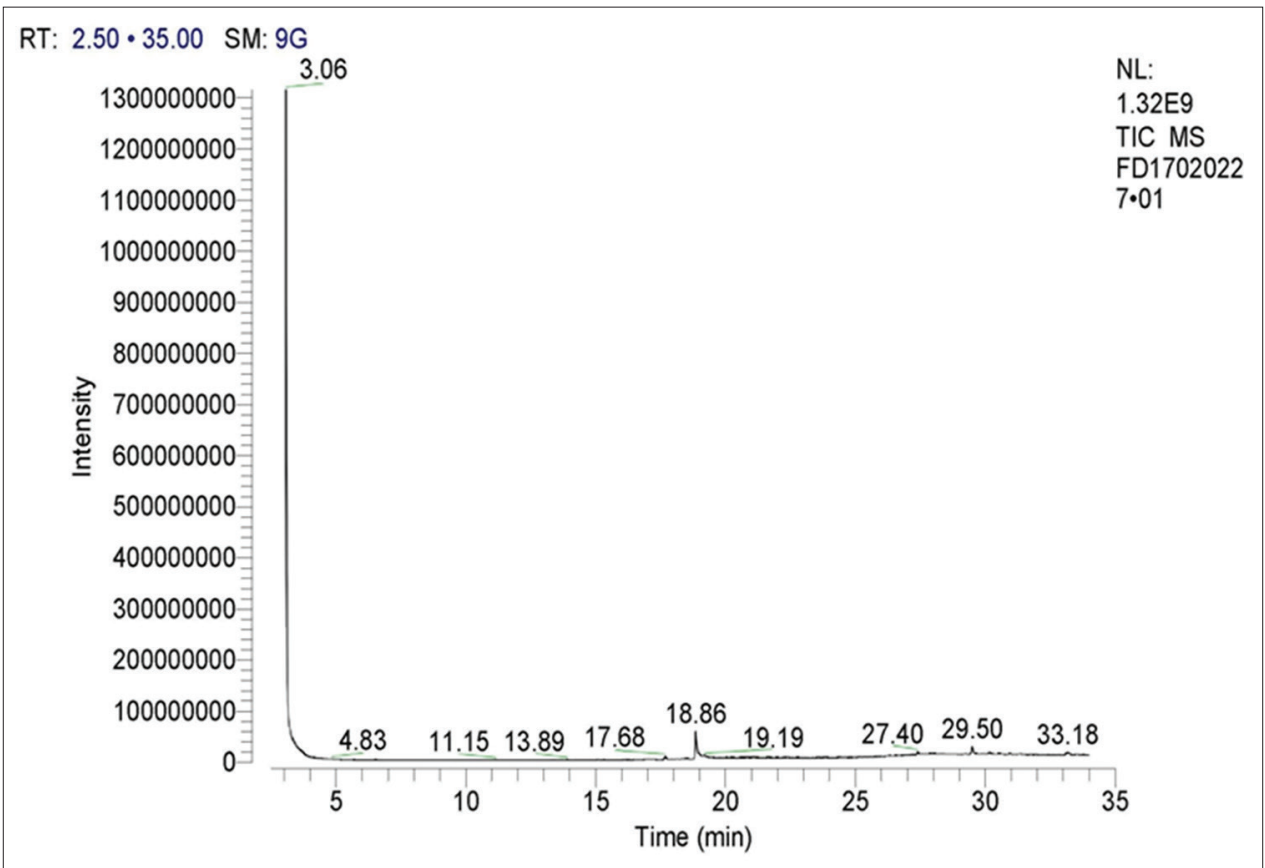

Fig. 1: Gas chromatography-mass spectrometry chromatogram of ethanol extract of Cymodocea serrulata

Table 1: Phytocompounds identified in ethanol extract of $C$. serrulata by GCMS

\begin{tabular}{|c|c|c|c|c|c|}
\hline S.NO. & Retention time & Compound name & Molecular formula & Molecular weight & Peak area $\%$ \\
\hline \multirow[t]{2}{*}{1.} & 17.68 & $\begin{array}{l}\text { 2Pentadecanone, 6,10,14trimethyl (Hexahydrofarnesyl } \\
\text { acetone) }\end{array}$ & C18H360 & 268 & 7.70 \\
\hline & & 2Undecanone, 6,10dimethyl & $\mathrm{C} 13 \mathrm{H} 26 \mathrm{O}$ & 198 & 7.70 \\
\hline 2. & 18.52 & Hexadecanoic acid, methyl ester (Palmitic acid) & $\mathrm{C} 17 \mathrm{H} 3402$ & 270 & 14.11 \\
\hline \multirow[t]{3}{*}{3.} & 18.86 & nHexadecanoic acid & C16H32O2 & 256 & 62.89 \\
\hline & & Tetradecanoic acid (Myristic acid) & $\mathrm{C} 14 \mathrm{H} 2802$ & 228 & 62.89 \\
\hline & & Pentadecanoic acid & C15H3002 & 242 & 62.89 \\
\hline \multirow[t]{2}{*}{4.} & 27.40 & Stigmasterol & $\mathrm{C} 29 \mathrm{H} 48 \mathrm{O}$ & 412 & 5.88 \\
\hline & & Cholesta4,6dien3ol & $\mathrm{C} 27 \mathrm{H} 440$ & 384 & 5.88 \\
\hline 5. & 29.50 & Stigmasta5,22dien3ol, acetate, & $\mathrm{C} 31 \mathrm{H} 5002$ & 454 & 19.42 \\
\hline
\end{tabular}

GCMS: Gas chromatography-mass spectrometry, C. serrulata: Cymodocea serrulata 
Table 2: Biological activity of identified compounds present in the ethanol extract of $C$. serrulata

\begin{tabular}{|c|c|c|c|c|}
\hline S. NO. & Compound name & Structure & Nature of compound & Biological activity \\
\hline 1 & Hexadecanoic acid (Palmitic acid) & & Fatty acid & $\begin{array}{l}\text { Antioxidant, } \\
\text { hypocholesterolemic, } \\
\text { nematicide, pesticide, } \\
\text { antiandrogenic } \\
\text { flavor, hemolytic, } \\
\text { and alpha-reductase } \\
\text { inhibitor [5] }\end{array}$ \\
\hline 2. & Stigmasta5,22dien3ol (Stigmasterol) & & Steroids & $\begin{array}{l}\text { Antiosteoarthritic, } \\
\text { antihypercholesterolemic, } \\
\text { cytotoxicity, antitumor, } \\
\text { hypoglycaemic, } \\
\text { antimutagenic, antioxidant, } \\
\text { anti-inflammatory, and CNS } \\
\text { effects [6]. }\end{array}$ \\
\hline 3. & Cholesta4,6dien-3-ol, & & Steroids & $\begin{array}{l}\text { Wound healing property, } \\
\text { skin protective property, } \\
\text { and antioxidant activity [7]. }\end{array}$ \\
\hline 4. & Hexahydrofarnesyl acetone & & Essential oil & $\begin{array}{l}\text { Antihypertensive activity, } \\
\text { vasodilation effect toward } \\
\text { cerebral, and basilar } \\
\text { artery [8]. }\end{array}$ \\
\hline 5. & Tetradecanoic acid (myristic acid) & & Fatty acid & $\begin{array}{l}\text { Antioxidant, cancer } \\
\text { preventive, nematicide, } \\
\text { hypercholesterolemic, and } \\
\text { lubricant }[9,10] .\end{array}$ \\
\hline 6. & Pentadecanoic acid & & Fatty acid & $\begin{array}{l}\text { Many odd length amino } \\
\text { acids are derived from } \\
\text { pentadecanoic acid. Act as } \\
\text { a biological marker for the } \\
\text { dietary milk intake [11]. }\end{array}$ \\
\hline
\end{tabular}

C. serrulata: Cymodocea serrulata

The myristic acid (Tetradecanoic acid) is an essential fatty acid has the variety of application in the beauty industry as fragrance ingredients, opacifying agent, surfactant, cleansing agent, and emulsifier. Mainly, it has been applied as a lubricant since it has a high rate of absorption by the skin. Myristic acid is a membrane stabilizer as they act as a lipid anchor for proteins [16]. It plays a role in energy storage as they increase LDL level. It has been reported that diabetic HDL- associated with myristic acid inhibits the stimulation of nitric oxide generation [17]. These findings have important implications regarding cardiovascular disease in diabetic patients.

The pentadecanoic acid is an odd chain saturated fatty acid with a 15 -carbon backbone is of exogenous origin not synthesized by the animal. It has been reported that it is seen highly in adipose tissue of person who intakes frequently dairy and fish food; thus, they act as a biomarker. The pentadecanoic acid act as a substrate for the synthesis of odd-numbered, very long-chain fatty acids which are glycosphingolipids in the brain. It provides anaplerotic intermediates for the citric acid cycle by a convert to propionyl-CoA and further into succinyl-CoA. It removes excess of propionic acid from the circulation [18]

Stigmasterol is a phytosterol produced by various medicinal plants were found to be in a higher component in ethanol extract of $C$. serrulata. Stigmasterol is a precursor for the synthesis of progesterone [19]. Since they are the intermediate in the biosynthesis of Vitamin D3, they act as an antiosteoarthritic [20]. It is also an intermediate in androgen, estrogen, and corticoids biosynthesis. Stigmasterol can inhibit cholesterol biosynthesis by inhibiting sterol $\Delta 24$-reductase in human Caco-2 and HL-60 cell lines; thus, they are the suppressor of hepatic cholesterol. Stigmasterol shows decrease in hepatic lipid peroxidation and increase in the activities of catalase, superoxide dismutase, and glutathione; thus, they are the good antioxidant [21].

Hexahydrofarnesyl acetone is a terpene ketone reported to possess long-lasting antihypertensive activity in spontaneous hypertensive rat without altering the heart rate [22]. Some amount of cholesta4,6-dien-3-ol, is seen ethanol extract of $C$. serrulata which can act as an antioxidant and also possess wound healing property. The major chemical component of ethanol extract of $C$. serrulata identified by GCMS is saturated fatty acids, which possess significant biological activity.

\section{CONCLUSION}

The GCMS analysis of ethanol extract of $C$. serrulata revealed the presence of the compound that has some ecological significance. The finding of these chemical components justifies their use as a remedy for the various ailments traditionally by our ancestors. The possession 
of antioxidant, anticancer, and anti-inflammatory property proved that C. serrulata can act as a nutraceutical and as ayurvedic medicine in this disease evolving world. Further studies aiming to evoke the uses of C. serrulata as the food and medicine are needed.

\section{AUTHOR'S CONTRIBUTION}

Pushpa Bharathi.N has performed the experiment, collected the data, and drafted the manuscript. Jayalakshmi.M has made significant involvement in the interpretation of data and revising the manuscript. Amudha.P participated in the proofreading of the manuscript. Vanitha.V designed the study and manuscript.

\section{CONFLICT OF INTERESTS}

There is no conflict of interest between authors.

\section{REFERENCES}

1. Lee SH, Jeon YJ. Anti-diabetic effects of brown algae-derived phlorotannins, marine polyphenols through diverse mechanisms. J Fitoterapia 2013;86:129-36.

2. Harrison PG. Control of microbial growth and of amphipod grazing by water-soluble compounds from leaves of Zostera marina. Mar Biol 1982;67:225-30

3. Bharathi NP, Amudha P, Vanitha V. Sea grasses-novel marine nutraceuticals. Int J Pharm Bio Sci 2016;7:567-73.

4. Hardoko, Primaoktasa D, Yuli E. Anticancer potential of Sea grass leaves Cymodecea serrulata CRUDE extract on HeLa cell. J Chem Pharm Res 2016;8:571-6.

5. Papitha R, Ravi L, Selvaraj CI. Phytochemical studies and GCMS analysis of Spermadictyon suaveolens roxb. Int J Pharm Pharm Sci 2017;9:143-9

6. Kaur N, Chaudhary J, Jain A, Kishore L. Stigmasterol: A comprehensive review. Int J Pharm Sci Res 2011;2:2259-65.

7. Sayık A, Yusufoğlu AS, Acık L, Arslan L. DNA-binding, biological activities, and chemical composition of wild growing Epilobium angustifolium L. Extracts from Canakkale, Turkey. J Turkish Chem Soc A 2017;4:811-40.

8. Shin WS, Oh S, An SW, Park GM, Kwon D, Ham J, et al. 5E- and 5Z-farnesylacetones from Sargassum siliquastrum as novel selective L-type calcium channel blockers. J Vasc Pharmacol 2013;58:299-306.

9. Dabadie H, Peuchant E, Bernard M, LeRuyet P, Mendy F. Moderate intake of myristic acid in sn-2 position has beneficial lipidic effects and enhances DHA of cholesteryl esters in an interventional study. J Nutr
Biochem 2005; $16: 375-82$.

10. Selvamangail C, Bhaskar A. GC-MS analysis of phytocomponents in the methanolic extract of eupatorium triplinerve. Int J Drug Dev Res 2012;4:148-53.

11. Warensjö E, Jansson JH, Cederholm T, Boman K, Eliasson M, Hallmans G, et al. Biomarkers of milk fat and the risk of myocardial infarction in men and women: A prospective, matched case-control study. Am J Clin Nutr 2010;92:194-202.

12. Sharma D, Rani R, Chaturvedi M, Yadav JP. Antibacterial capacity and identification of bioactive compounds by GCMS of Allium cepa. Int J Pharm Pharm Sci 2018; 10:116-21.

13. Schmelzle H, Wirth S, Skopnik H, Radke M, Knol J, Böckler HM, et al. Randomized double-blind study of the nutritional efficacy and bifidogenicity of a new infant formula containing partially hydrolyzed protein, a high beta-palmitic acid level, and nondigestible oligosaccharides. J Pediatr Gastroenterol Nutr 2003;36:343-51.

14. Okoh O, Grosspietzsch R, von Klitzing L. Is the intake of palm oil (palmitic acid) in meals associated with the low incidence of respiratory distress syndrome in Nigeria? (author's transl). Monatsschr Kinderheilkd 1979;127:669-74

15. Zhang L, Ji J, Zhu XY, Wu YY, Yu H, Zhang B, et al. Palmitic acid induces apoptosis in human hepatoma cell line, HepG2 cells. Zhongguo Yi Xue Ke Xue Yuan Xue Bao 2004;26:671-6.

16. William Still Well. An Introduction to Biological Membranes Composition, Structure and Function. $2^{\text {nd }}$ ed. London: Elseiver: Academic Press; 2016. p. 89-110.

17. Dorr P. Therapeutic Areas II: Cancer, Infectious Diseases, Inflammation And immunology and dermatology comprehensive medicinal chemistry II. Reference Module in Chemistry, Molecular Sciences and Chemical Engineering. USA: Elsevier; 2007. p. 419-43.

18. Golley RK, Hendrie GA. Evaluation of the relative concentration of serum fatty acids C14:0, C15:0 and C17:0 as markers of children's dairy fat intake. Ann Nutr Metab 2014;65:310-6.

19. Arunkumar R, Nair SA, Subramoniam A. Induction of cell-specific apoptosis and protection of mice from cancer challenge by a steroid positive compound from Zornia diphylla (L.) Pers. J Pharmacol Pharmacother 2012;3:233-4

20. Kametani T, Furuyama H. Synthesis of vitamin D3 and related compounds. Med Res Rev 1987;7:147-71.

21. Batta AK, Xuab G, Honda A, Miyazaki T, Salen G. Stigmasterol reduces plasma cholesterol levels and inhibits hepatic synthesis and intestinal absorption in the rat. J Pharm Sci 2006;55:292-9.

22. Shin WS, Oh S, An SW, Park GM, Kwon D, Ham J, et al. 5E- and 5Z-farnesylacetones from Sargassum siliquastrum as novel selective L-type calcium channel blockers. Vascul Pharmacol 2013;58:299-306. 